\title{
Methodical Approaches to the Development of Embankment Arrangement Projects
}

\author{
Vadim Danilchenko and Vitaliy Kasyanov \\ Moscow State University of Civil Engineering, Yaroslavskoe shosse 26, Moscow, 129337, Russia
}

\begin{abstract}
: the main research question is the problem of methodological approaches to the development of embankment arrangement projects. Recently, in our country, great importance has been attached not only to the improvement or reconstruction of embankments, but also to comprehensively addressing many issues, such as the preservation of the historical heritage of our culture, ecology, safety, economy, multifunctionality, etc. The aim of the study is a systematic integrated approach to solving the tasks of arranging embankments, the proposed systems perform several functionals at once and allow to solve environmental, technical, aesthetic and economic problems. To solve the problem of arranging embankments, normative documents, domestic and foreign experience, innovative technologies, modern materials and advanced methods for improving embankments were studied.
\end{abstract}

\section{Introduction}

First of all, the embankment is a specialized place of a settlement, where it is possible to spend a free time for city residents and its guests, including physical activity (cycling and walking) and intellectual feast (enjoying nature, city views, gardening, etc. ) [1-2]. It means that it performs several functions at once: paths for cyclists and pedestrians, as an alternative for mothers with prams.

Here there are also recreation areas for adults and children where they can play games; benches and podium areas for entertainment, information corners and cafeterias, elaboration of architectural and sculptural elements with landscaping. Moreover, all the above components of the embankment improvement project should be combined both aesthetically and functionally. These functions are transport-recreational and aesthetic [34].

\section{Materials and Methods}

The modern use of open space, harmoniously entering the image of the urban environment, is aimed at creating comfort for the population that meets the aesthetic, physical and spiritual needs of a person. [5]

When developing the landscape of the embankment, one aspect, that is aimed at harmonious combination of the interaction of the population to water resources and reasonable design of public urban spaces, has to be taken into account [6].

\footnotetext{
*Corresponding author: vadim.dkr@mail.ru
} 
The project of giving comfort and aesthetics to the territories located along the banks of the water arteries includes a thorough study of all the necessary zones aimed at creating a certain functionality that is combined with the environment. Improvement of the embankment sites and its entire infrastructure as a whole requires a competent approach to planning and landscaping, and pedestrian traffic and functional zoning [7].

\section{Results and Discussion}

As a result of the analysis of examples from domestic and foreign practice, it is clear that the creation of projects of comfortable embankments contains a huge potential associated with the essential requirements of the population. But the most important aspects of such design are, first of all, the design of options for access to water resources available to citizens, as well as cleaning the river and maintaining (and, if necessary, restoring) biological diversity, coupled with a harmonious connection with the general architectural ensemble of the settlement [ 8-9].

According to the results of consideration of acquaintance with modern options for the improvement of embankments, a tendency emerges there to create a certain compositional plan inseparably related to comfort and multifunctionality [10].

A special place in the development of projects for the improvement of embankments is occupied by green plantings - both tree-shrub, and decorative-floral. The choice of the above plantings is based on the principles that meet the decorative requirements, as well as phytocenotic and environmental requirements. The visual moments are taken into account the consonant forms of the crown and the coloring of shrubs and trees, including those with attractive flowering [11-13].

For example, in Moscow, in order to develop the reconstruction of the Kadashevskaya Embankment, its historical moments should be taken into account. The embankment was built on the place where Kadashevskaya Khamovnaya settlement was located in the 17th century. The first mention of Kadash was seen in the will, made by Ivan III in 1504 according to a new style. Kadashi - that is, coopers, who worked for the needs of the prince - were its main population, and gave the name of the settlement. Kad is a barrel, a tub. The 16th century is marked by the consolidation of the place as the center of the city's khamovnoe production. Khamovnoe - that is, textile. Kadashevsky khamovny dvor, which was a linen manufactory, later became the Sovereign Mint.

The embankment was built, based on the "Projected Plan", approved in 1775, and the result of the work was quite good for the capital. Along the red line there were buildings of the same type with central driveways and benches located on the first floors. In the last decade of the 20th century - the beginning of the 21st century, a significant part of the buildings was liquidated.

The improvement of the area, coupled with its landscaping, is a well-organized and interrelated distribution of landscaping objects in terms of a certain area (settlement), harmoniously combined with its general structure [14].

The main aspects of creating a gardening system for any area are considered to be their uniform distribution, equal access to them for citizens and city services, their coherence and continuity. The role of the coastal strip in the appearance of the city is very important, since the coastal strip is not only a part of the architectural and planning structure of the city, but is also designed to perform a variety of functions. For example, such as economic, transport, recreational, environmental and, finally, economical [15-22]. 


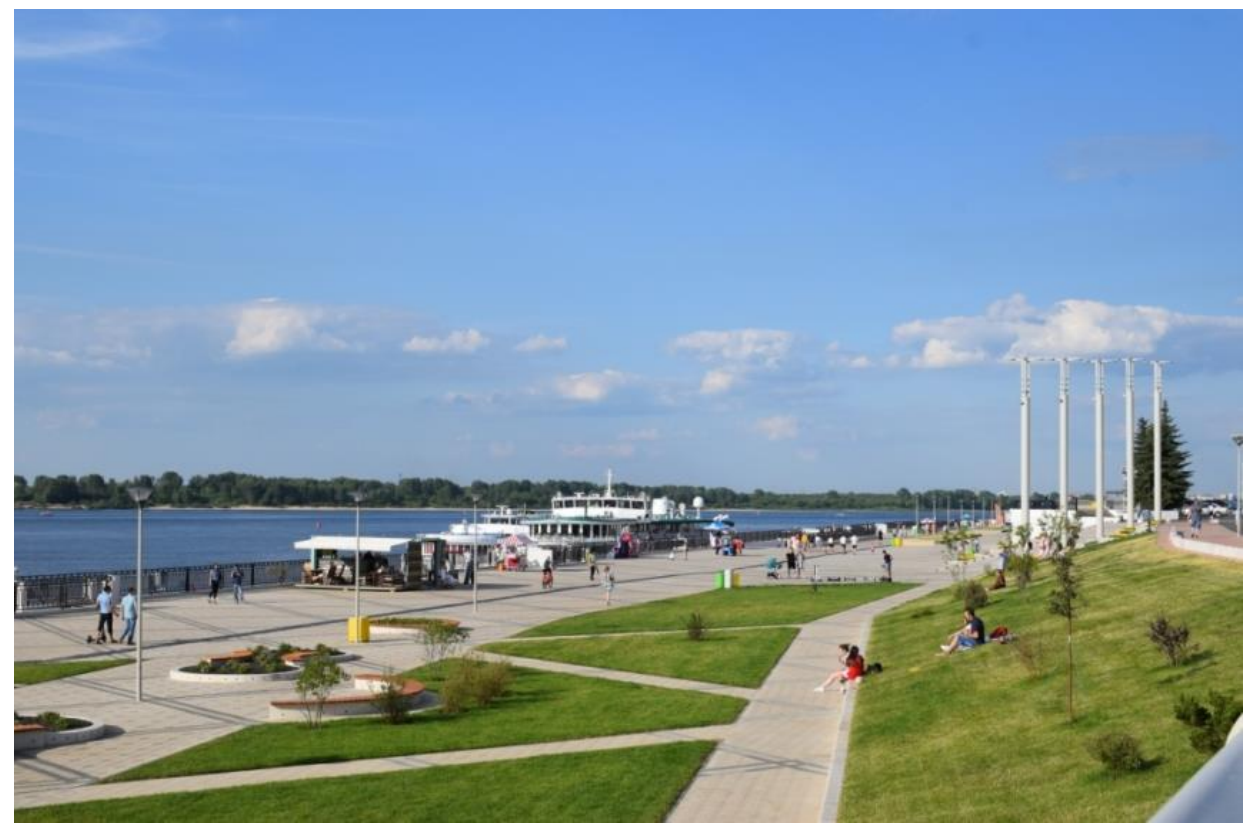

Fig. 1. Nizhnevolzhskaya Embankment in Nizhny Novgorod.

When developing each section stretching along the waterway, it is extremely important to consider the future designation of the territory when planning activities related to improvement and engineering protection. Such activities include the construction of walkways and embankments, berths and descents, as well as the improvement of beach areas [6].

Due to the high cost of designing the entire coastal strip, it is more important to economically divide it into certain sections, each of which will carry its own specific load. In this case, the basin principle of separation should be applied and after that, the implementation of projects by sectors should begin. [15,18]

In the process of implementing these works, not only the problems of designing the medical and recreational environment of leisure for citizens and creating recreation areas are being solved, but also designing a set of systems that is necessary to keep the coastal zone clean due to water treatment and drainage systems [13].

In cases when the improvement of the coastal zone does not perform the necessary functions, the shores of the waterway are more exposed to negative impacts associated with, for example, mechanical damage, soil erosion, etc.

That's why the improvement of the banks of rivers and reservoirs and their equipment with engineering-protective complexes are extremely important. These problems should be solved in accordance with certain specific conditions. For example, due to the development and improvement of embankments [23].

The embankment may include the following options for improvement, performing many important functions: beaches, recreation areas, sports grounds, marinas, etc. An important role is played by the design of the coastal zone through landscaping (squares, parks and alleys for walking), as well as certain architectural solutions, such as viewing and recreational grounds, water exits, arbours, etc. [13] 


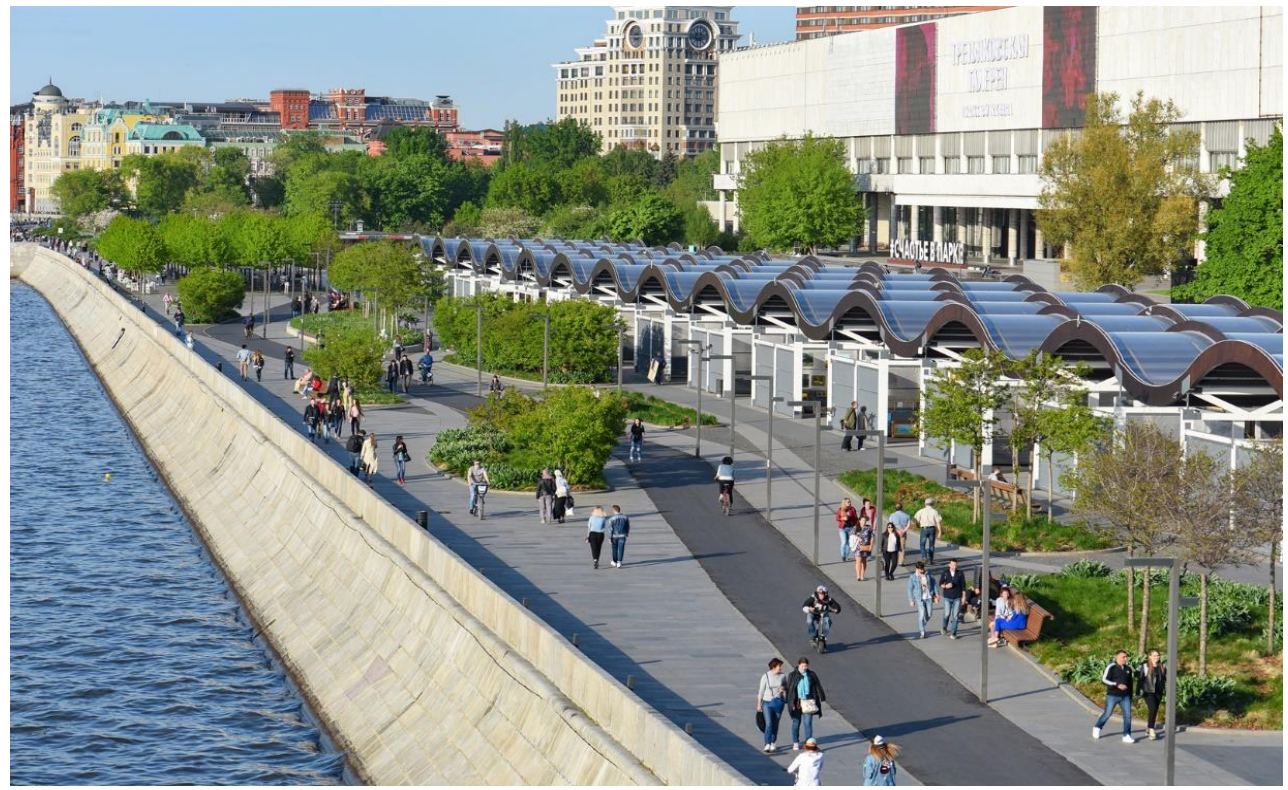

Fig. 2. Krymskaya Embankment in Moscow.

In order to select the relevant option of the landscape-ecological arrangement of floodplain and coastal lands, one should carefully consider the mode of their operation. [23] This approach requires the maintenance of the ecological system of the area adjacent to the waterway, the maximum preservation of the biological corridor, as well as the activation of the water protection functionality of the floodplain, etc.

It is necessary to follow the basic principles of biosphere organization in order to intervene in the natural ecological system of areas as little as possible, namely: systematic creation of the biogenic circulation and maintaining the diversity of living organisms, for which measures are taken to preserve, maintain and restore characteristic for a particular locality groups and species of living organisms [16].

The following factors should be considered to understand how suitable this or that area is in terms of recreation and reconstruction:

- functional, which includes geological and climatic conditions, as well as hydrographic and vegetable;

- hygienic, responsible for assessing the state of water bodies and the air environment, the degree of wetland, etc ;

- aesthetic, which includes the visual harmony of the surrounding area (exotic, panoramic, landscapes and relief features).

For planning the arrangement of the area, the presence of a concept and a project is obligatory, in which the main idea of the transformation is indicated, taking into account ecological and aesthetic aspects. Such aspects as socio-economic, natural, traditional, environmental, climate, etc. are important. This also includes the general architecture of the area and the presence of green spaces, both natural for the environment and culturally introduced [11].

When planning the improvement of embankments, one should not ignore the risks - for example, possible river floods or floods, soil erosion, etc. In order to minimize these risks as much as possible, it is important not to forget about the following activities that need to be carried out before the improvement plan:

- the lowering the floodplain, aimed at expanding the river bed in case of flooding; 
- the lowering the bun, ensuring the stability of the desired depth of the water artery and increasing, if necessary, the flow rate;

- the movement of the dam into the terrain in order to increase the capacity of river water;

- the removal of obstacles by converting or mixing, allowing, if necessary, to increase the flow rate;

- the depolderization, aimed at the formation of an area for overflows in case of flooding;

- the creation of a reservoir, which can act as a nearby lake. This option will avoid water shortages during an emergency situation;

- the measures to deepen the channel, aimed at creating a greater capacity of the waterway;

- the creation of a canal intended for the discharge of flood waters and representing a certain part of the dike diverted from the main river bed;

- the measures to strengthen the dikes in those areas where the expansion of the river is not required.

Environmental assessment of projects in any construction industry is an integral part of the creation of almost any construction. It is obligatory to consider the safety of materials and components used in the construction; for example, mercury and chromium, as well as lead and cadmium, are recognized as dangerous to the health of living organisms. The presence of those in building and finishing materials threatens the life and health of people. $[18,20]$

Having considered the projects of reconstruction and arrangement of Crimea (carried out within the framework of the federal target program of the socio-economic development of the region for the improvement of the embankments of Crimea) in such cities as Yevpatoria, Koktebel, Saki, Simeiz, as well as the embankments in Moscow and etc., in the regions of the Russian Federation (by Denis Kharlanov, Sergey Kuznetsov, E Kuricheva, and others) made the following conclusions that it was necessary not only to "patch holes" in certain problems, but also to change the attitude towards methodological approaches to developing projects and arranging embankments. In the future, the embankments should become real "pearls" of architecture that meet the spiritual and physical needs of a person.

\section{Conclusions}

In this century, when construction is rapidly developing, a new approach to the quality of standard reconstruction and maintenance of buildings is required, the main measures of which should be the comfort and safety of the population - both physically and physiologically, as well as the respect for relevant standards of environmental friendliness and ergonomics together with energy efficiency.

The main aspects of the design defined in this work allow us to create and apply new long-term architectural and planning options for the reconstruction and recreation of areas.

\section{References}

1. Kasyanov, V., Landysheva, O. Problems and prospects of cottage construction in Russia. MATEC Web of Conferences 106, 06022 (2017). DOI: https://doi.org/10.1051/matecconf/201710606022.

2. Sokova S.D. Smirnova N.V. Reliability assessment of waterproofing systems of buildings underground parts. IOP Conf. Series: Materials Science and Engineering $\mathbf{3 6 5}$ (2018) 052028 doi:10.1088/1757-899X/365/5/052028. 
3. Dement'eva M.E. Integrated technique of planning the capital repair of residential buildings and objects of transport infrastructure. IOP Conf. Series: Earth and Environmental Science, 90, 012052 (2017) DOI: https://doi.org/10.1088/17551315/90/1/012052.

4. Dement'eva M. Evaluation of exploitation suitability of enclosing structures of filling stations. MATEC Web of Conferences, 117, 00037 (2017) DOI: https://doi.org/10.1051/matecconf/201711700037.

5. Korol, E.A., Kustikova, Y.O. Constructive systems, load-bearing and enclosing structures of high-rise buildings. E3S Web of Conference 2018.

6. Korol E.A., Gaydysheva Y., Passmore D. Integration of organizational-technological and social aspects in the realization of the program of renovation of residential development. Journal MATEC Web of Conferences, Volume 251, 06025 (2018). DOI: https://doi.org/10.1051/matecconf/201825106025.

7. Dement'eva M. Cartographic modeling for monitoring the technical condition of urban development objects. MATEC Web of Conferences, 170, 01079 (2018) DOI: https://doi.org/10.1051/matecconf/201817001079.

8. Varlamov A.A., Rimshin V.I., Tverskoi S.Y. Planning and management of urban environment using the models of degradation theory (IOP Conference Series: Earth and Environmental Science 177(1),012040, 2018).

9. Kas'yanov V.F. Kargin A.N. Komochkov M.M. Mitin M.F. Effect of boration on the activity induced in concretes by proton bombardment. Soviet Atomic Energy (1983)

10. Varlamov A A, Rimshin V I, Tverskoi S Y Security and destruction of technical systems (IFAC-PapersOnLine 51(30), 2018).

11. Borkovskaya V.G., Degaev E., Burkova I. Environmental economic model of risk management and costs in the framework of the quality management system // MATEC Web of Conf., 193 (2018) 05027. DOI: https://doi.org/10.1051/matecconf/201819305027.

12. Borkovskaya V.G. Project Management Risks in the Sphere of Housing and Communal Services. Journal MATEC Web of Conferences, Volume 251, 06025 (2018). DOI: https://doi.org/10.1051/matecconf/201825106025.

13. Kas'yanov V.F. Danilchenko V., Amelin V.,Tolmachev V. Environmental risk management. Forecasting and modeling of emergency risk management. Journal MATEC Web of Conferences, Volume 251, $06030 \quad$ (2018). DOI: https://doi.org/10.1051/matecconf/201825106030.

14. Korol O., Shushunova N., Lopatkin D., Zanin A., Shushunova T. Application of Hightech Solutions in Ecodevelopment. Journal MATEC Web of Conferences, Volume 251, 06025 (2018). DOI: https://doi.org/10.1051/matecconf/201825106002.

15. Borkovskaya V, Passmore D. Application of Failure Mode and Effects Analysis in Ecology in Russia. MATEC Web of Conf., 193 (2018) 05027. DOI: https://doi.org/10.1051/matecconf/201819305026.

16. Polyakova V., Degaev E.,Pierre El Haddad. Reduction of Ecological and Economic Risks in Utilization of Solid Domestic Wastes and Construction Waste. MATEC Web of Conferences 251, 06017 (2018). DOI: https://doi.org/10.1051/matecconf/201825106017.

17. Borkovskaya V.G. Complex models of active control systems at the modern developing enterprises. Advanced Materials Research (Volumes 945-949). Chapter 22: Manufacturing Management and Engineering Management. June 2014. Pages 30123015. DOI: 10.4028/www.scientific.net/AMR.945-949.3012.

18. Borkovskaya V.G. Environmental and economic model life cycle of buildings based on the concept of "Green Building".Applied Mechanics and Materials 467. Materials Science and Mechanical Engineering. Chapter 2: Building Materials and Construction 
Technologies. Pages 287-290. December 2013. DOI:

10.4028/www.scientific.net/AMM.467.287.

19. Borkovskaya V.G. Post bifurcations of the concept of the sustainable development in construction business and education. Advanced Materials Research. (Volumes 860863). Chapter 26: Engineering Education. Pages 3009-3012. December 2013. DOI: 10.4028/www.scientific.net/AMR.860-863.3009.

20. Borkovskaya V.G. The concept of innovation for sustainable development in the construction business and education. Applied Mechanics and Materials. (Volumes 475-476). Chapter 15: Engineering Management. December 2013. Pages 1703-1706. DOI: 10.4028/www.scientific.net/AMM.475-476.1703.

21. Degaev E.N. New classification of Foaming Agents for Fire Extinguishing. MATEC Web of Conferences. 193, 02032 (2018). DOI: https://doi.org/10.1051/matecconf/201819302032.

22. Degaev E., Orlov A., Pierre El Haddad, Pleshivtsev A. Ecological and Economic Risks of Fire Protection of Warehouses and Tank Parks. MATEC Web of Conferences. 251, 06013 (2018).DOI: https://doi.org/10.1051/matecconf/201825106013

23. Kas'yanov V.F. Lavdanskii P.A. Activation of concretes based on granite and limestone rubble. Soviet Atomic Energy (1983) 